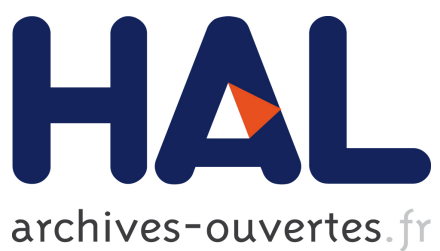

\title{
A MINIATURE SQUID MAGNETOMETER FOR BIOMAGNETIC MEASUREMENTS WITH IMPROVED SELECTIVITY
}

\author{
J. Overweg, M. Walter-Peters
}

\section{To cite this version:}

J. Overweg, M. Walter-Peters. A MINIATURE SQUID MAGNETOMETER FOR BIOMAGNETIC MEASUREMENTS WITH IMPROVED SELECTIVITY. Journal de Physique Colloques, 1978, 39 (C6), pp.C6-1226-C6-1227. <10.1051/jphyscol:19786542>. <jpa-00218030>

HAL Id: jpa-00218030

\section{https://hal.archives-ouvertes.fr/jpa-00218030}

Submitted on 1 Jan 1978

HAL is a multi-disciplinary open access archive for the deposit and dissemination of scientific research documents, whether they are published or not. The documents may come from teaching and research institutions in France or abroad, or from public or private research centers.
L'archive ouverte pluridisciplinaire HAL, est destinée au dépôt et à la diffusion de documents scientifiques de niveau recherche, publiés ou non, émanant des établissements d'enseignement et de recherche français ou étrangers, des laboratoires publics ou privés. 


\title{
A MINIATURE SQUID MAGNETOMETER FOR BIOMAGNETIC MEASUREMENTS WITH IMPROVED SELECTIVITY
}

\author{
J.A. Overweg and M.J. Wa1ter-Peters \\ Twente University of Technology, P.O. Box 217, Enschede, The Netherlands
}

\begin{abstract}
Résumé.- La surface effective d'une spire circulaire par rapport à un champ magnétique uniforme est notablement réduite quand elle est située près d'un grand disque supraconducteur. Elle 1 'est beaucoup moins dans le cas d'une source dipolaire proche. Un arrangement de ce type est utilisé pour construire un petit gradiomētre au premier ordre avec une ligne de base de $3 \mathrm{~cm}$. La sensibilité au champ d'une source proche est comparable à celle d'un gradiomètre au deuxième ordre beaucoup plus grand, mais 1 'influence des sources parasites est beaucoup moins importante. Un autre avantage de la configuration asymétrique est que son inductance est plus petite que celle d'un gradiomètre conventionnel, de sorte qu'un meilleur transfert de flux au SQUID est possible.

Abstract.- The effective area of a circular wire loop to a uniform field is reduced considerably if it is placed close to a large superconducting disc. The effective area to the field of a nearby magnetic dipole is reduced much less. Such a selective pickup loop is used to construct a small first order gradiometer, with a baseline of $3 \mathrm{~cm}$. Its sensitivity to fields of nearby sources is comparable to that of a much larger symetric second order gradiometer wheras its sensitivity to inhomogeneous magnetic noise is much less. Another advantage of the unsymetric configuration is, that it has a smaller selfinductance than a conventional gradiometer, so that a better flux transfer to the sQuID is possible.
\end{abstract}

INTRODUCTION.- In most SQUID-magnetometer systems the external magnetic fields to be measured are coupled into the SQUID by a fluxtransformer. If the magnetic signal is much smaller than other ambient fields this fluxtransformer has usually the form of a first or second order gradiometer /1/.

In order to obtain the maximum signal to noise ratio the baseline, i.e. the distance between the gradiometer loops, should be as small as possible, provided that the flux coupled into the SQUID remains large compared to its own noise. Hence the $\mathrm{S} / \mathrm{N}$ ratio will increase on reducing the length of the gradiometer without loss of sensitivity.

A SELECTIVE PICKUP LOOP.- The baseline of a gradiometer can be reduced considerably if it is possible to construct a pickup loop with an effective area that depends on the shape of the external magnetic fields : small for uniform fields and large for the inhomogeneous fields that have to be measured. A small second loop will then be sufficient for nulling the response to uniform fields (figure la) so that inhomogeneous fields will produce a large flux in the SQUID, even when the baseline is very short (figure 1b). It will be shown, that the combination of a circular loop of wire close to a large superconducting disc behaves like the selective fluxtransformer loop we need.
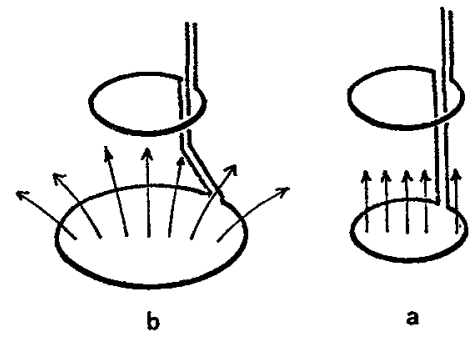

Fig. I : A gradiometer with one selective pickup loop as seen by a) a uniform magnetic field b) the field of a nearby source.

When a superconducting disc of radius a is placed on the axis of a circular loop of radius $r$ at a distance $d$ the effective area of the loop will be reduced. The effective area of the system to a uniform field along the axis is given by /2/

$A_{\text {eff }}=A_{0}+2\left(a^{2} v-\frac{d^{2}}{v}\right)\left(1-\left(v+\frac{1}{v}\right) \operatorname{arccotg} v\right)$

where $A_{0}$ is the area of the loop itself and $\nu$ is the positive root of

$a^{2} v^{4}+\left(a^{2}-r^{2}-d^{2}\right) v^{2}-d^{2}=0$

Figure 2 presents a graph of eq. (1) for the case that $\frac{a}{r}=1.6$, together with corresponding measurements. The graph also shows the measured effective area of the system for the field of a nearby magnetic dipole. For small values of $d / r$ the effective. area to a uniform field is much smaller than to the 
field of the dipole.

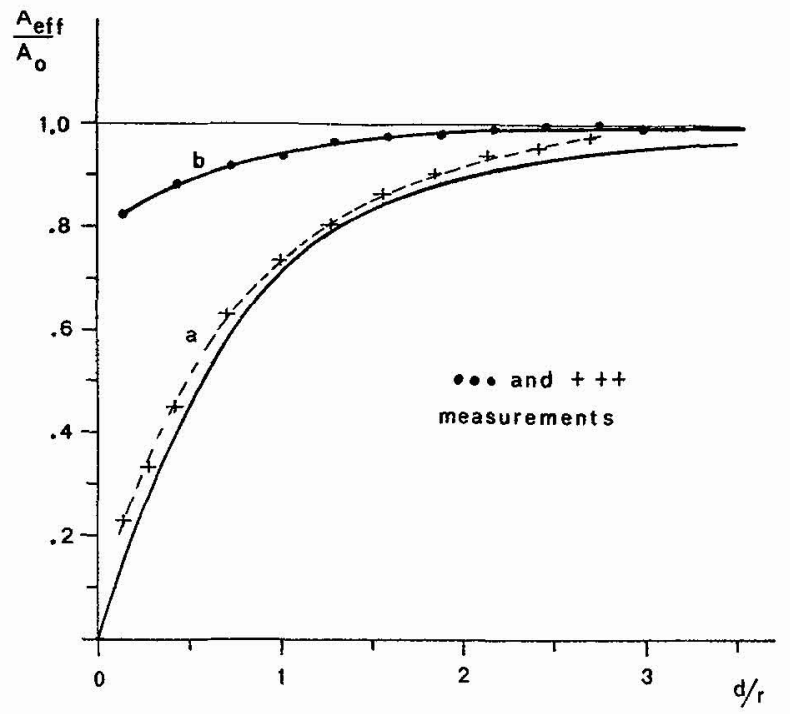

Fig. 2 : Effective area of a loop of radius $r$ as a function of its distance d to a large superconducting disc of radius $a$. The ratio $a / r$ is 1.6 . a) for uniform field along the axis (measured and calculated). b) for the field of a dipole on the axis of the system at a distance $S=13 \mathrm{r}$ (measured).

THE NEW MAGNETOMETER.- Figure 3 shows the prototype of magnetometer with one selective pickup loop. A large lead disc is located just $2 \mathrm{~mm}$ above the 1ower pickup loop. Its distance to the upper loop is so large, that the reduction of the effective area of this loop is only a few percent. The magnetic signal is detected by a homemade toroìdal pointcontact SQUID located on top of the large lead disc. For balancing in axial direction the effective area of the upper loop can be reduced up to $5 \%$ by a second superconducting disc, that can be moved along the axis of the magnetometer. The testing of the new device has just started and precise data about its performance are not yet available. The total noise level has been dominated by the noise of the SQUID because this was not properly adjusted. But other results look promising. The sensitivity of the magnetometer to magnetic noise, such as the field of a small magnet at a few meters distance or the 50 and $150 \mathrm{~Hz}$ magnetic noise is much less than of a second order gradiometer of the same sensitivity. Because the new fluxtransformer has a smaller selfinductance than a conventional gradiometer of the same effective area a better flux transfer to the SQUID is possible /3/. The measu- red fluxreduction factor is 85 and this figure can still be improved by better matching the signal coil of the SQUID to the transformer.

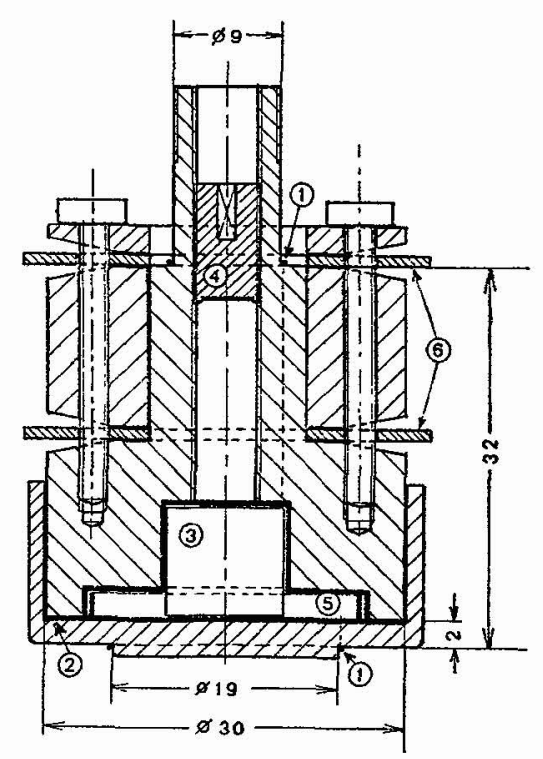

Fig. 3 : Miniature magnetometer with one selective pickup loop. 1) wire loops $0.04 \mathrm{~mm} \mathrm{Nb}$ multifilament wire, 2) lead disc, 3) toroìdal SQUID, 4) screw with superconducting disc for balancing in axial direction, 5) shielded enclosure for capacitor and wire connections, 6) teflon rings for clamping against wa11 of dewar.

\section{References}

/1/ Opfer,J.E., Yeo,Y.K., Pierce,J.M. and Rorden, L.H., A superconducting second derivative gradiometer I.E.E.E. on magn., Dec. 1974 P. 536

/2/ Overweg,J.A. and Walter-Peters,M.J. ; Improving the balance of a gradiometer for low level magnetometry by adjustable superconducting vanes. to be published.

/3/ Claassen, J.H. ; Coup1ing considerations for SQUID devices ; J. App1. Phys. 46 (1975) 2268 